\title{
Os "novos" mercados e sua contribuição para a inclusão produtiva dos agricultores familiares no Tocantins
}

\author{
Diego Neves de Sousa \\ Embrapa Pesca e Aquicultura - Palmas - TO - Brasil \\ ORCID: http://orcid.org/0000-0003-3124-5150
}

\begin{abstract}
Resumo
Os "novos" mercados são construções sociais baseadas em especificidades que decorrem dos processos de diferenciação dos produtos. Este artigo analisa a contribuição dos "novos" mercados para a inclusão produtiva dos agricultores familiares e, em seguida, discute quais mercados as políticas públicas têm potencializado no estado do Tocantins. Na metodologia utilizou-se da técnica de entrevistas, as quais foram realizadas junto a extensionistas rurais e gestores públicos que atuam com os públicos da agricultura familiar. Os resultados sugerem que o diferencial dos "novos" mercados é a reaproximação entre os agricultores familiares e os consumidores. Conclui-se que os mercados institucionais, fomentado pelas políticas públicas: Programa de Aquisição de Alimentos (PAA) e Programa Nacional de Alimentação Escolar (PNAE), além das feiras locais, são os principais mercados acessados pelos agricultores familiares. Por sua vez, os extensionistas são considerados fundamentais para fazer a "ponte" para a inserção dos agricultores nesses "novos" mercados e também no acesso das políticas públicas que os potencializam.
\end{abstract}

Palavras-chave: Políticas públicas. Mercados institucionais. Feiras locais. Desenvolvimento rural. Agentes multiplicadores.

The "new" markets and their contribution to the productive inclusion of family farmers in the state of Tocantins, Brazil

\section{Abstract}

The "new" markets are social constructions based on specificities that result from the processes of product differentiation. This article analyzes the contribution of the "new" markets to the productive inclusion of family farmers and then discusses which markets public policies have been potentiating in the state of Tocantins. The methodology used the technique of interviews, which were carried out with rural extension workers and public managers who work with the public of family farming. The results suggest that the differential of the "new" markets is the rapprochement between family farmers and consumers. It is concluded that institutional markets, fostered by public policies: Food Acquisition Program (PAA) and National School Feeding Program (PNAE), in addition to local fairs, are the main markets accessed by family farmers. In turn, extension workers are considered essential to "bridge" the gap for the insertion of farmers in these "new" markets and also for access to public policies that empower them. 
Keywords: Public policies. Institutional markets. Fairs locals. Rural development. Multiplying agents.

\section{Los "nuevos" mercados y su contribución a la inclusión productiva de los agricultores familiares en el estado de Tocantins, Brasil}

\section{Resumen}

Los "nuevos" mercados son construcciones sociales basadas en especificidades que resultan de los procesos de diferenciación de productos. Este artículo analiza la contribución de los "nuevos" mercados a la inclusión productiva de los agricultores familiares y luego discute qué mercados se han potenciado las políticas públicas en el estado de Tocantins. La metodología utilizó la técnica de entrevistas, las cuales se llevaron a cabo con extensionistas rurales y administradores públicos que trabajan con el público de la agricultura familiar. Los resultados sugieren que el diferencial de los "nuevos" mercados es el acercamiento entre agricultores familiares y consumidores. Se concluye que los mercados institucionales, impulsados por políticas públicas: Programa de Adquisición de Alimentos (PAA) y Programa Nacional de Alimentación Escolar (PNAE), además de las ferias locales, son los principales mercados a los que acceden los agricultores familiares. A su vez, los extensionistas se consideran esenciales para hacer la "puente" para la inserción de los agricultores en estos "nuevos" mercados y también para el acceso a políticas públicas que los empoderen.

Palabras clave: Políticas públicas. Mercados institucionales. Ferias locales. Desarrollo Rural. Agentes multiplicadores.

\section{Introdução}

Os "novos" mercados são construções sociais baseadas em especificidades decorrentes de processos de diferenciação, tais como: as especialidades de nicho, orgânicos, artesanais, solidários e institucionais (WILKINSON, 2008). Eles estão imersos nos mercados em geral, mas são relativamente diferenciados em virtude de arranjos institucionais e infraestruturas peculiares (WU; DING; YE, 2016). Nestes mercados, "as relações econômicas estão imersas em redes de relações sociais, políticas e culturais que funcionam como instituições que orientam as práticas e geram um sistema de regras e dispositivos que regulam o ordenamento da vida social" (SCHNEIDER, 2016, p.118). Por essa razão, esses novos mercados aparecem como forma de compensar as deficiências dos mercados convencionais e, ao mesmo tempo, como uma forma de resistir a eles (YE; WANG, 2011).

As organizações da agricultura familiar têm avançando na construção desses novos mercados, apostando no reconhecimento de produtos com características diferenciadas e ancorados nos recursos dos territórios rurais. No entanto, o desenvolvimento dessas iniciativas ainda carece de maior apoio do Estado na criação de políticas públicas que, ao mesmo tempo, valorizem os produtos da agricultura familiar e restrinjam os processos de apropriação e descaracterização dos mesmos por outros atores (BELIK, 2016). Considerando a diversidade da agricultura familiar, as políticas de desenvolvimento rural deveriam ser baseadas em "um modelo de mercados múltiplos" (NIEDERLE, 2017), na tentativa de atender as especificidades dos diferentes públicos beneficiários.

Embora existam unidades familiares capitalizadas que se inserem competitivamente em diversas cadeias convencionais de commodities, esta opção 
está distante da realidade da maioria dos agricultores mais vulneráveis, os quais não conseguem se adaptar ao treadmill tecnológico promovido pela dinâmica destas cadeias. Assim, a adequação das estratégias de inclusão produtiva ${ }^{1}$ à formação de mercados viáveis para diferentes grupos de agricultores implica em importante desafio para o estado e, em particular, para os agentes multiplicadores da Assistência Técnica e Extensão Rural (Ater). Em face disso, este artigo analisa a percepção desses agentes sobre a contribuição dos "novos" mercados para a inclusão produtiva dos agricultores familiares, bem como, identifica quais mercados as políticas públicas para a agricultura familiar têm potencializado.

A pesquisa foi realizada no estado do Tocantins, cujo meio rural é caracterizado por repertórios culturais diversificados, abarcando uma pluralidade de povos tradicionais associados à diversidade dos biomas (cerrado, floresta amazônica e pantanal), dos produtos da sociobiodiversidade (coco babaçu, pequi, buriti, mangaba etc.) e das identidades sociais (indígenas, quilombolas, quebradeiras de coco etc.) (MENESTRINHO; PARENTE, 2011). A formação do rural tocantinense passou por significativas transformações, principalmente para a população de ribeirinhos, pescadores artesanais e de agricultores familiares que foram impactados por grandes empreendimentos e que tiveram que ser reassentados em outras localidades. Além disso, a construção de novos mercados nesse estado é dificultada pela limitada estrutura de produção; dificuldades no acesso ao crédito, à extensão rural e aos mercados; deficiências nas estruturas de processamento e distribuição de seus produtos; baixo nível de organização social e produtiva; e também pela falta de recursos dos municípios interioranos para o funcionamento do serviço de inspeção sanitária (SOUSA, 2019b).

A pesquisa é de natureza qualitativa, baseada principalmente na realização de entrevistas com os agentes multiplicadores de Ater e de gestores públicos que estão inseridos em redes sociotécnicas ${ }^{2}$ que atuam junto aos diferentes grupos de agricultores familiares no âmbito do estado do Tocantins. Entre os meses de maio e agosto de 2018 foram realizadas 80 entrevistas com informantes que atuam em 22 municípios tocantinenses e em 28 instituições que atuam direta e indiretamente com os públicos da agricultura familiar. Destaque para Palmas, capital do estado do Tocantins, onde foram realizadas a maior quantidade de entrevistas diante do fato de que a sede das instituições está neste município.

Para sistematizar, categorizar e tornar possível o tratamento dos dados utilizou-se da análise de conteúdo do tipo temática (BARDIN, 2011). Para isso, três etapas fizeram parte deste procedimento: pré-análise; exploração do material; bem como tratamento dos resultados obtidos a partir da pesquisa de campo e interpretação, com o apoio do software NVivo.

O artigo está organizado em quatro seções, além desta introdução que apresentou o problema de pesquisa e a metodologia adotada neste estudo. $\mathrm{Na}$ segunda seção o foco foi discutir à luz da literatura o debate sobre mercados convencionais e alternativos no contexto da agricultura familiar. Na quarta seção

\footnotetext{
${ }^{1}$ Sobre o que se entende por inclusão produtiva ver os estudos de Sousa e Niederle (2018) e Sousa (2019b).

${ }^{2}$ Hubert (1997) define redes sociotécnicas como o relacionamento de diversos atores sociais e institucionais que se mobilizam para a construção da inovação, a circulação de conhecimentos e de recursos.
} 
foram apresentados os principais resultados da pesquisa de campo ilustrados pelas narrativas dos entrevistados. E, por último, as conclusões finais apontaram que os mercados institucionais e as feiras locais foram os principais mercados acessados pelos agricultores familiares, além de que os extensionistas rurais são considerados fundamentais para fazer a "ponte" entre esses "novos" mercados e o acesso as políticas públicas.

\section{0 debate sobre mercados convencionais e alternativos}

As políticas e os programas que se mostraram mais exitosos na promoção da inclusão produtiva dos agricultores familiares estão mais evidentes na terceira geração de políticas para a agricultura familiar, a qual destaca a construção de mercados para a promoção da segurança alimentar e a sustentabilidade ambiental (GRISA; SCHNEIDER, 2014; SOUSA, 2019b).

Neste caso, a política que teve maior visibilidade foi o Programa de Aquisição de Alimentos, criado em 2003, para articular a compra de produtos provenientes da agricultura familiar com ações de Segurança Alimentar e Nutricional (SAN) para populações vulneráveis. Dada a visibilidade do Programa e sua capilaridade, ganhou relevância seu efeito para a dinamização das economias locais e fortalecimento das organizações coletivas da agricultura familiar, o que promoveu ainda mais o debate sobre a construção social de "novos" mercados agroalimentares (ABRAMOVAY, 2009). Já em 2009, com algumas similaridades ao PAA, o Programa Nacional de Alimentação Escolar foi redesenhado e passou a exigir que, pelo menos, 30\% dos recursos governamentais para a alimentação escolar fossem utilizados para aquisição de produtos provenientes de agricultores familiares e de seus empreendimentos coletivos (BRASIL, 2009).

Em linhas gerais, nos últimos anos, proliferaram ações governamentais e, também, da sociedade civil que articulam redes agroalimentares alternativas como forma de incluir os agricultores familiares em mercados ditos não convencionais. Citam-se, como exemplos, os circuitos curtos, produtos diferenciados da sociobiodiversidade, movimentos da economia solidária, mercados institucionais, denominação de origem, indicação geográfica, certificação, marcas coletivas, dentre outras opções. Trata-se, assim, de estratégias para o reconhecimento das peculiaridades dos modos de vida da agricultura familiar e da dinâmica diferenciada desses "novos" mercados que tem aguçado o debate em diversas arenas públicas com o propósito de ampliar as potencialidades dos mesmos para a proposição de um novo modelo de desenvolvimento rural (MARQUES, CONTERATO; SCHNEIDER, 2016).

Este fato é motivado pela criação de redes alternativas do sistema agroalimentar que estariam pautadas por valores territoriais que estão imersos em construções e convenções sociais, pelas quais atribuem aos alimentos outras formas de julgamento e valoração ligados aos aspectos sociais e culturais de determinada região em que são produzidos e consumidos. Apregoa-se, assim, que esse abastecimento alimentar - pautado em novas formas de produção e de relação intrínseca entre produtores e consumidores - é capaz de construir práticas pautadas em valores e racionalidades transformadores (GOODMAN; DUPUIS; GOODMAN, 2012). 
A partir do novo contexto da agricultura brasileira (e do desenvolvimento rural) e sua relação emergente com as questões alimentares e de mercados alternativos, verifica-se que a lógica do mercado convencional não dá margem (ou existem maiores limitações) para que o agricultor familiar se insira nele de maneira competitiva. Esses mercados hegemônicos são, cada vez mais, controlados por algumas poucas empresas multinacionais que, no sistema agroalimentar, têm sido conhecidas como "impérios alimentares" (PLOEG, 2008). Por outro lado, a lógica dos mercados alternativos revela que os agricultores familiares e suas organizações coletivas estão buscando se inserirem em novas redes sociotécnicas que tem como objetivo proteger espaços específicos contra os "impérios alimentares". Isto possibilita a construção de trajetórias de desenvolvimento rural que ultrapassem as limitações inerentes a lógica do mercado convencional (PLOEG, 2011).

De modo geral, a ênfase dos novos mercados recaiu nas formas alternativas de produção e consumo de alimentos focado na preocupação maior de se atentar a criação, operacionalização e consolidação dessas novas relações sociais no interior do sistema agroalimentar (PLOEG et al., 2000), além de se atentar ao crucial papel desempenhado pelos consumidores na construção das redes agroalimentares de comércio e do processo de (re)localização da produção de alimentos (GOODMAN, DUPUIS, GOODMAN; 2012). Pois, assim, é possível entender as implicações intrínsecas na construção de mercados alternativos que tenham como pré-requisito primordial a qualidade, ou seja, que valorizem os aspectos sociais e culturais dos territórios que emergem a produção local de alimentos numa perspectiva de virada para a qualidade (quality turn) (GOODMAN, 2003).

A dicotomização existente entre os mercados ditos convencionais (ligado às questões globais) e alternativos (ligado às questões locais) em torno do contexto da agricultura familiar tem a ver com a dificuldade de delimitar os atores sociais presentes e as fronteiras que os perpassam. Mas, por outro lado, verifica-se que esses mercados se revelam consideravelmente bem relacionados, híbridos e concorrentes entre si (SONINO; MARSDEN, 2006).

A diferenciação desses dois tipos de mercado é resultado dos múltiplos enfoques característicos de cada um. Os mercados convencionais são aqueles atrelados as cadeias globais de valor das commodities, controlados por transnacionais sem vínculo com a localidade e que tem a finalidade de standardização de produtos, processos e pessoas. Em contrapartida, os mercados alternativos são reconhecidos a partir da localidade em que estão inseridos e na relação direta entre compradores e vendedores numa lógica de cadeias curtas com a capacidade de (re)ssocialização e (re)espacionalização dos alimentos baseados em especificidades do meio rural (NIEDERLE; SCHUBERT; SCHNEIDER, 2014).

No entanto, "enquanto a dinâmica das cadeias globais de mercadorias está na agenda de estudo há longa data, permanecem indagações sobre as expressões e as compreensões dos "novos" mercados" (NIEDERLE; SCHUBERT; SCHNEIDER, 2014, p. 43), motivados por este ser ainda incipiente na dinâmica socioeconômica dos agricultores familiares e nas práticas dos agentes multiplicadores de Ater. Para isso, nos últimos anos, os estudos rurais têm despertado maior interesse na perspectiva de analisar os mercados não convencionais, rompendo com as relações de oferta e demanda e priorizando as relações entre agricultor e consumidor com vistas à construção social dos mercados. 


\title{
3 Resultados e discussão
}

A representação social do mercado convencional para os agricultores familiares mais pobres quase sempre é de uma imagem negativa, conforme salientam os entrevistados nesta pesquisa. A explicação fundamenta-se na ideia de que (quase sempre) para escoar sua produção, o agricultor depende da figura do atravessador que intercepta parte de sua produção (e consequentemente da renda gerada), pois compra o produto a um preço abaixo daquele de mercado, inclusive quando se trata de produtos com qualidades diferenciadas e com forte demanda, como é o caso dos alimentos orgânicos.

Uma entrevistada explica que, em geral, os extensionistas trabalham incentivando os agricultores a não usarem nenhum tipo de produto químico em sua produção, o que lhes possibilitaria atender a um nicho de mercado em franca expansão. Mas isto também é um dos motivos do aumento de atravessadores, os quais buscam este tipo de produto para revender a preços elevados. $O$ atravessador se dirige as propriedades rurais onde é difícil o acesso para o escoamento da produção e, diante disso, diminuem as opções do agricultor para negociar como é ilustrado na fala abaixo.

\begin{abstract}
A pessoa chega lá e diz: - Eu pago tanto na sua produção - Você vai fazer o que? Vai deixar perder ou vai vender pelo preço que te ofereceu? Mesmo que seja abaixo do mercado. Então, para mim, esses dois fatores: a questão da distância e a questão das estradas, de infraestrutura, têm localidades que não tem ponte, tem localidade que eles não conseguem chegar carro nessas comunidades, né? Então isso é um fator que só garante $o$ isolamento dessas comunidades, não garante a inclusão deles, nem produtiva, nem social, nem nada (entrevistado $n^{\circ} 4$ ).
\end{abstract}

Os agricultores familiares tocantinenses têm sérias dificuldades em escoar sua produção para o mercado formal visto que nem sempre conseguem atender a todas as exigências higiênico-sanitárias. Por isso,

[...] tem que estar lá com seu registro e eles não têm isso para os seus produtos. Então se não for de uma forma in natura ainda há uma perspectiva, mas fora isso, o comércio, às vezes, quer comprar, mas é impedido por conta de tudo isso (entrevistado $n^{\circ} 1$ ).

Os resultados evidenciados na pesquisa corroboram para afirmar que 0 problema do controle sanitário talvez seja o principal problema para a inserção da produção tradicional dos agricultores familiares nos mercados, conforme indicado pela maioria dos entrevistados e também apontado pela literatura (CRUZ; MENASCHE, 2014; SOUSA et al., 2019). No exemplo abaixo, em uma das narrativas extraídas da pesquisa de campo, verifica-se o quão recorrente é este gargalo nas feiras livres e a desconexão que existe entre o Estado e os órgãos de inspeção para orientar os agricultores no que tange a um projeto adequado para balizar a construção das unidades de processamento.

O principal gargalo que a gente tem na comercialização dos produtos é o processo da inspeção sanitária. Isso é um problema sério, aqui na feira em 
Palmas, lá têm aqueles queijos, nenhum tem SIF, não tem nada, eles estão lá, entendeu? Para as prefeituras, o estado do Tocantins criou um monte de unidades de processamento de mandioca, de polpa, de mel, praticamente todas as que foram construídas pelo estado não tem SIF. Pois é, o próprio estado, é uma coisa curiosa, faziam as plantas, entendeu? O Estado implantava, daqui há pouco chegava a inspeção sanitária - Não, aqui faltou um buraco, aqui faltou não sei o quê - Então, acho que os agricultores tentaram e tentam se organizar, mas é uma normativa que realmente os impedem de participar efetivamente dos mercados (entrevistado $n^{\circ} 2$ ).

Este gargalo fez com que os agentes multiplicadores refletissem sobre a fundamental importância em discutir e propor ações efetivas para o Sistema de Inspeção Sanitária proveniente da produção artesanal da agricultura familiar visto que, em 2016, a Companhia Nacional de Abastecimento (Conab), unidade do Tocantins, deixou de adquirir a farinha de mandioca pelo PAA, produto considerado um dos principais da cultura alimentar regional, em virtude das dificuldades dos agricultores em obterem a licença da vigilância sanitária. Cruz e Menasche (2014) consideram que, ao ser reconhecido os diferentes modos de vidas rurais, abre-se também a oportunidade para que os alimentos tradicionais sejam valorizados pelas características e qualidades que lhes são próprios, o que ocasionaria em sua preservação cultural e, consequentemente, sua inserção no mercado formal.

Também chama a atenção os questionamentos feitos por alguns agentes multiplicadores de Ater ao expressarem que, muitas das vezes, as práticas intervencionistas deles são pautadas por uma proposta baseada na diversificação da produção, o que, por outro lado, nem sempre contribui para a seleção de um produto reconhecido como "carro chefe" para a comercialização. A pressuposição é que

[...] daqueles produtos que dá rentabilidade na propriedade, tenho que eleger um que possa ser aperfeiçoado tecnologicamente ou usar as tecnologias sustentáveis para melhorar a produtividade e ter a capacidade de competir no mercado (entrevistado $n^{\circ} 11$ ).

Em outras palavras, os agentes em geral apuram a necessidade de articular com o agricultor ações estratégicas para que possam melhorar a eficiência produtiva de alguns cultivos que demonstrem peculiaridades e qualidades e, assim, serem enquadrados como "carro chefe" do referido agricultor para inserção nos mercados, preferencialmente os alternativos.

Os mercados alternativos são reconhecidos a partir da localidade em que estão inseridos e na relação direta entre compradores e vendedores numa lógica de cadeias curtas com a capacidade de (re)ssocialização e (re)espacionalização dos alimentos baseados nas especificidades do meio rural em questão (NIEDERLE; SCHUBERT; SCHNEIDER, 2014; PLOEG; JINGZHONG; SCHNEIDER, 2012). Os "novos" mercados que têm maior potencialidade de inclusão dos agricultores familiares são aqueles que permitem a devida reprodução dos seus modos de vida. Nesta perspectiva, os entrevistados apontaram que os principais mercados alternativos que os agricultores familiares tocantinenses têm acesso são as feiras locais e os mercados institucionais. 
As feiras livres, até pouco tempo, eram consideradas como modelo arcaico de relações mercantis cuja extinção inevitável dependeria do ritmo de expansão das grandes redes varejistas. Hoje, por outro lado, elas voltam a ocupar significativos espaços públicos em diversos municípios brasileiros (NIEDERLE, 2017). No estado do Tocantins não é diferente. Isto se deve, em grande medida, a ação de agentes multiplicadores como os extensionistas do Instituto de Desenvolvimento Rural do Tocantins (Ruraltins), órgão oficial de Ater, os quais estão mobilizando a criação e a revitalização de feiras livres específicas para a comercialização dos produtos provenientes da agricultura familiar. Como destaca um dos entrevistados, em vários municípios

[...] conseguiram organizar feiras propriamente de agricultores. Eles são cadastrados pelo Ruraltins e têm reuniões periódicas. Eles [extensionistas] que organizaram todo aquele espaço, no local e dia que a cidade disponibiliza para feiras abertas (entrevistado $n^{\circ} 23$ ).

Os agentes multiplicadores informam ainda que as feiras são incentivadas por serem "mais um" canal de comercialização dos agricultores e também como forma de não ficarem dependente de políticas públicas de comercialização, haja vista que, recentemente, houve vultuosos cortes no orçamento público para vários programas neste segmento (NIEDERLE et al., 2019).

O ambiente das feiras também é local de trocas comerciais e sociais, o que corrobora para ampliar as possibilidades de inclusão em outros mercados. Neste intento, a importância de fomentar as feiras está no fato de que elas contribuem para dinamizar as cadeias curtas de comercialização, assim como mencionado por um entrevistado:

[...] deve-se ter uma atenção para o que a gente chama de cadeias curtas de comercialização. Se eu estou aqui em Palmas, o ideal é que os agricultores da região tivessem produzindo e atendessem a toda produção demandada e essa viesse também para as feiras (entrevistado $\left.n^{\circ} 22\right)$.

Quanto ao mercado institucional, criado na última década, o mesmo buscou articular a cooperação entre Estado, agricultores familiares e movimentos rurais na perspectiva de atender a demanda do consumidor. Essa iniciativa tornou-se preponderante vetor do desenvolvimento rural, ao possibilitar estratégias de combate à pobreza rural e inclusão produtiva, tendo como expoentes o PAA e o Programa Nacional de Alimentação Esoclar (PNAE). O primeiro foi criado a partir da narrativa construída pelos debates da fome e da segurança alimentar e nutricional. Já o segundo, foi suscitado por alterações que ocorreram na legislação da alimentação escolar, permitindo integrar ações voltadas para a educação alimentar e nutricional junto aos escolares e a inclusão produtiva dos agricultores familiares.

Segundo Grisa e Porto (2015), as principais mudanças observadas no contexto das novidades do mercado institucional foram que:

a) as aquisições dos gêneros alimentícios fossem fundamentalmente provenientes dos agricultores familiares, com maior preocupação ao atendimento da diversidade socioeconômica e cultural enraizada na recém-criada categoria sociopolítica da agricultura familiar;

b) estímulo à comercialização de um conjunto variado de produtos; 
c) compras em circuitos curtos de comercialização como forma de aproximação entre agricultores e consumidores;

d) aquisições por produtos agroecológicos e que atendam às necessidades dos consumidores e, por último;

b) $\mathrm{o}$ fortalecimento da segurança alimentar e nutricional dos beneficiários consumidores.

Neste contexto, a dinâmica de funcionamento dos mercados institucionais está estritamente ligada ao que se denomina de nested markets (mercados aninhados), no qual Ploeg (2011) explica que é um tipo de mercado singular protegido de alguma forma, principalmente diante das relações sociais e da hegemonia instaurada pelos mercados convencionais. O diferencial é que, por ser regulado pelo poder público e também gerar um bem comum a segmentos socialmente vulneráveis, o mercado institucional torna-se fundamental para a redução da pobreza e uma alternativa crucial de inclusão produtiva para os agricultores familiares via mercado.

No entanto, os agentes multiplicadores relataram nesta pesquisa que é comum os agricultores não conhecerem os Programas de Compras Governamentais. Mas, também, tem o caso daqueles que conhecem, embora não saibam os trâmites necessários para acessá-los, e aqueles que não têm nenhum interesse em acessá-los. Para minimizar situações desse tipo, uma entrevistada enfatizou que é de fundamental importância a participação dos agricultores em reuniões de diferentes redes sociotécnicas para que possam ter mais conhecimento sobre como acessar as políticas públicas desta categoria sociopolítica, em especial as que promovem a inserção de agricultores em mercados.

Entre os agentes multiplicadores de Ater é perceptível o quanto vislumbram o mercado institucional sob uma lógica diferenciada, qual seja: de um mercado que tem a sensibilidade em reconhecer as peculiaridades e demandas dos agricultores familiares. Outro ponto evidenciado é a forte ligação dos mercados institucionais com os aspectos da produção de alimentos saudáveis e com qualidade. Em uma das narrativas sistematizada nesta pesquisa, averígua-se o posicionamento do quão importante é o papel social da agricultura familiar e sua estrita relação com o mercado institucional, apesar de seus produtos serem considerados de maior valor devido suas particularidades.

[A agricultura familiar] produz um monte de produtos extremamente importantes, saudáveis e de qualidade, mas viu o preço? Ele não é tão barato, porque não é uma produção de escala. Mas vale a pena pagar um preço por um produto que é mais saudável, que vai garantir uma população vivendo no campo, já que a gente entende que não adianta inchar a cidade para que ela se exploda, o importante é ter uma política, como a das Compras Governamentais, que ao mesmo tempo concilia a lógica produtiva dos agricultores familiares (entrevistado $n^{\circ} 43$ ).

Ao ter dado condições para a agricultura familiar escoar sua produção num mercado destinado somente a ela, constatou-se indícios do aumento da capacidade produtiva e do nível de planejamento da produção agrícola do agricultor. Isto foi um marco na política agrícola brasileira, na qual "o produtor passou a ter um monte de coisa, vende isso, vende aquilo, começou a processar, a fazer não sei o que mais" (entrevistado $\mathrm{n}^{\circ} 2$ ). Além disso, o agricultor passou a se engajar em processos de 
diversificação produtiva, tal como comentado por um respondente: "Quando os Programas surgiram, houve diversificação produtiva muito grande, saiu a questão do gado e abriu outras possibilidades, que é interessante para o desenvolvimento e estabilização da sociedade" (entrevistado $n^{\circ} 19$ ).

Frente a isso, o mercado institucional se mostrou como opção viável de inclusão produtiva para os agricultores familiares, segundo os entrevistados. Este resultado também é a conclusão a que chega o estudo de Caldas e Anjos (2015), o qual expressa que os mercados institucionais permitiram romper com a ideia polarizada entre mercado e exclusão social, bem como com o imaginário de que o combate e a redução da pobreza devam ocorrer no mesmo parâmetro das políticas de transferência de renda. Além disso, vislumbram que a dinâmica de funcionamento dos mercados institucionais proporciona efeitos positivos pelos quais devem ser vistos como uma ferramenta estratégica para alavancar o desenvolvimento rural.

Em um estudo realizado no Tocantins sobre os programas governamentais de aquisição de alimentos da agricultura familiar, constatou-se que poucos agricultores tiveram acesso. Isto foi em decorrência aos problemas atrelados à burocracia da legislação, baixo nível de organização produtiva, falta de estruturas mínimas de processamento de produtos e deficitário ou inexistente serviço de assistência técnica (SOUSA et al, 2018).

Com um discurso pautado pela ideia de que "produzir eu sei, eu não sei é comercializar", na opinião de um dos entrevistados, os agricultores demonstram que uma das fragilidades em que se encontram é referente à gestão profissionalizada da propriedade, principalmente no que diz respeito aos aspectos da comercialização. Como é que eu vou gerenciar isso? Como é que eu vou calcular para saber se estou tendo lucro ou prejuízo? Como é que eu sei qual atividade é a que gera mais retorno, ou seja, qual é a mais vantajosa para se comercializar? Essas são perguntas recorrentes que os agentes multiplicadores de Ater reportam aos agricultores, mas que nem sempre conseguem ter a devida resposta. Em virtude desta situação, os agentes explanam para a necessidade dos agricultores participarem ativamente de capacitações (tanto técnica quanto na esfera da gestão) para atenuar os problemas que são recorrentes na propriedade e que poderiam ser minimizados com maior fluxo de informações e de transferência de tecnologias.

Por isso da importância do serviço de extensão rural para orientar as práticas de manejo dos agricultores e, concomitantemente, indicar qual mercado e qual política pública são mais adequados para acessar a fim de escoar a produção. Assim, um dos papéis do extensionista rural é construir a seguinte problematização junto ao agricultor: "Se você vai produzir tal produto, aí você tem esse mercado e tem aquele outro mercado, qual deles quer acessar?" (entrevistado $\left.n^{\circ} 14\right)$. Em outras palavras, é dar opções ao agricultor de quais mercados é possível acessar diante da realidade do mesmo, embora sejam poucos os que permitem sua reprodução socioeconômica, autonomia e empoderamento. Então, a alternativa viável está nos "novos" mercados que estão enraizados em laços sociais que reaproximam os agricultores familiares dos consumidores. Para isso, entram em cena qualidades e características socioculturais intrínsecas das diferentes categorias da agricultura familiar. 
Portanto, a construção de "novos" mercados está relacionada diretamente com o serviço de assessoria dos extensionistas rurais que aparecem como facilitadores de novas redes. Dessa maneira, os "novos" mercados têm se constituídos como o resultado do esforço de uma rede de atores onde, no centro, aparecem principalmente os extensionistas rurais dada a sua proximidade com os agricultores. Assim, para a promoção desses "novos" mercados, não apenas é importante ampliar a infraestrutura do sistema de Assistência Técnica e Extensão Rural, mas também qualificar os extensionistas rurais (e demais agentes multiplicadores) para atuarem como facilitadores das redes sociotécnicas que atuam com a agricultura familiar. As empresas oficiais de Ater tem capilaridade na maioria dos municípios brasileiros (BRASIL/FAO, 2003) e tocantinenses (SOUSA et al., 2018) e, assim, podem ter papel expressivo nos processos de inclusão produtiva e de transferência de conhecimentos e de tecnologias.

\section{Conclusão}

São múltiplos os mercados e espaços do meio rural em que os agricultores familiares podem buscar a inclusão produtiva, porém são poucos que permitem sua devida reprodução socioeconômica, autonomia e empoderamento, como categoria sociopolítica institucionalizada.

Uma das alternativas de inclusão produtiva dos agricultores familiares está nos "novos" mercados que estão enraizados e aninhados em laços sociais reaproximando os agricultores familiares dos consumidores no sistema agroalimentar localizado. No Tocantins destacam-se as feiras locais e os mercados institucionais, este último fomentado pelas políticas públicas: PAA e PNAE.

Outra evidência deste estudo é que a emergência de "novos" mercados está relacionada diretamente com o serviço de assessoria dos extensionistas rurais que aparecem como facilitadores de novas redes sociotécnicas que atuam com os públicos da agricultura familiar e que fazem a "ponte" para a inserção nesses "novos" mercados e também no acesso das políticas públicas que os potencializam.

\section{Agradecimentos}

Ao financiamento recebido pelo edital $n^{\circ}$ 07/2018 CNPQ/SESCOOP e, também, pelas contribuições e reflexões feitas pelo professor Paulo Niederle que corroboraram para a construção deste artigo.

\section{REFERÊNCIAS}

ABRAMOVAY, R. Anticapitalismo e inserção social dos mercados. Tempo social, São Paulo, v. 21, n. 1, p. 65-77, 2009. Disponível em:

http://www.scielo.br/pdf/ts/v21n1/v21n1a05.pdf. Acesso em: 30 mar. 2019.

BARDIN, L. Análise de conteúdo. São Paulo: Edições 70, 2011.

BELIK, W. Os limites para a expansão dos mercados locais. In: MARQUES, F. C; CONTERATO, M. A; SCHNEIDER, S. (org.). Construção de mercados e agricultura 
familiar: desafios para o desenvolvimento rural. Porto Alegre: Editora UFRGS, 2016. p.183-2005.

BRASIL. Ministério do Desenvolvimento Agrário - MDA; ORGANIZAÇÃO DAS NAÇÕES UNIDAS PARA A ALIMENTAÇÃO E A AGRICULTURA - FAO. Perfil das Instituiçõos de Assistência Técnica e Extensão Rural para Agricultores Familiares e Assentados no Brasil. Brasília: MDA/FAO, 2003.

BRASIL. Lei $\mathbf{n}^{\circ}$ 11.947, de 16 de junho de 2009. Dispõe sobre o atendimento da alimentação escolar e do Programa Dinheiro Direto na Escola aos alunos da educação básica; altera as Leis nos 10.880, de 9 de junho de 2004, 11.273, de 6 de fevereiro de 2006, 11.507, de 20 de julho de 2007; revoga dispositivos da Medida Provisória no 2.178-36, de 24 de agosto de 2001, e a Lei no 8.913, de 12 de julho de 1994; e dá outras providências, 2009.

CALDAS, N.V; ANJOS, F. S. As boas novas que vêm do campo: mercados institucionais e desenvolvimento rural no Sul do Brasil. In: CONGRESSO DE ESTUDOS RURAIS, 6., 2015, Lisboa. Anais[...] Lisboa: CER, 2015. Disponível em: http://cer2015.sper.pt/. Acesso em 02. fev. 2018.

CRUZ, F. T; MENASCHE, R. O debate em torno de queijos feitos de leite cru: entre aspectos normativos e a valorização da produção tradicional. Vigilância Sanitária em Debate: Sociedade, Ciência \& Tecnologia, Rio de Janeiro, v. 2, p. 34-42, 2014. Disponível em: https://bit.ly/2zhAvpv. Acesso em 01 out. 2019.

GOODMAN, D. The quality turn and alternative food practices: reflections and agenda. Journal of Rural Studies, v.19, n.1, p.1-7, 2003.

GOODMAN, D; DUPUIS, E; GOODMAN, M. Alternative food networks. London/New York: Routlege, 2012.

GRISA, C; PORTO, S. I. Dez anos de PAA: As contribuições e os desafios para o desenvolvimento rural. In: Políticas públicas de desenvolvimento rural no Brasil. GRISA, C; SCHNEIDER, S. (org.). Porto Alegre: Editora da UFRGS, 2015. p. 155-180.

HUBERT, B. Appui à l'agriculture familiale: appuis institutionnels et initiatives locales. Rapport de mission au Brésil, Montpellier: INRA-SAD, CIRAD-SAR, 1997.

MARQUES, F. C; CONTERATO, M. A; SCHNEIDER, S. (Orgs). Construção de mercados e agricultura familiar: desafios para o desenvolvimento rural. Porto Alegre: Editora da UFRGS, 2016.

MENESTRINHO, E; PARENTE, T. G. O estudo das territorialidades dos povos tradicionais. Brazilian Geographical Journal, Uberlândia, v. 2, p. 1-19, 2011. Disponível em: http://www.seer.ufu.br/index.php/braziliangeojournal/article/view/9157. Acesso em 05 jul. 2019.

NIEDERLE, P. A. Afinal, que inclusão produtiva? A contribuição dos novos mercados alimentares. In: DELGADO, G. C; BERGAMASCO, S. M. P. P. (org.). Agricultura familiar brasileira: desafios e perspectivas de futuro. Brasília: MDA, 2017. p. 166-194.

NIEDERLE, P. et. al. Narrative disputes over family-farming public policies in Brazil: conservative attacks and restricted counter movements. Latin American Research 
Review, Pittsburgh, v. 54, p. 707-720, 2019. Disponível em: https://larrlasa.org/articles/10.25222/larr.366/. Acesso em out. 2019.

NIEDERLE, P. A; SCHUBERT, M. N; SCHNEIDER, S. Agricultura familiar, desenvolvimento rural e um modelo de mercados múltiplos. In: DOULA, S. et. al. (org.). A agricultura familiar em face das transformações na dinâmica recente dos mercados. Viçosa: Suprema, 2014. p. 43-68.

PLOEG, J. D. Camponeses e impérios alimentares. Porto Alegre: UFRGS, 2008.

PLOEG, J. D. Trajetórias do desenvolvimento rural: pesquisa comparativa internacional. Sociologias, Porto Alegre, v. 13, n. 27, p. 114-140, 2011. Disponível em: https://bit.ly/2Yp57xA. Acesso em 29 jul. 2018.

PLOEG, J. D. et al. On regimes, novelties, niches and co-production. In: WISKERKE, J. S. C; PLOEG, J. D. (ed). Seeds of transition. Assen: Royal van Gorcum, 2004. p. 1-30.

PLOEG, J. D; et al. Rural development: from practices and policies towards theory. Sociologia Ruralis, v. 40, n. 4, pp. 391-407, 2000.

PLOEG, J. D; JINGZHONG, Y; SCHNEIDER, S. Rural development through the construction of new, nested, markets: comparative perspectives from China, Brazil and the European Union. Journal of Peasant Studies, Abingdon, v. 39, n. 1, p. 133173, 2012. Disponível em: https://bit.ly/2DOxLPg. Acesso em 18 mar. 2019.

SCHNEIDER, S. Mercados e agricultura familiar. In: MARQUES, F. C; CONTERATO, $M$. A; SCHNEIDER, S. (org.). Construção de mercados e agricultura familiar: desafios para o desenvolvimento rural. Porto Alegre: Editora UFRGS, 2016. p. 93-140.

SONINO, R; MARSDEN. T. Beyond the divide: rethinking relationships between alternative and conventional food neworks in Europe. Journal of Economic Geography, v. 6, p. 181-199, 2006.

SOUSA, D. N. Mediadores sociais e políticas públicas de inclusão produtiva da agricultura familiar no Tocantins: (des)conexões entre referenciais, ideias e práticas. 2019. Tese (Doutorado em Desenvolvimento Rural) - Curso de PósGraduação em Desenvolvimento Rural, Faculdade de Ciências Econômicas, Universidade Federal do Rio Grande do Sul, Porto Alegre, 2019a. Disponível em: https://lume.ufrgs.br/handle/10183/204079. Acesso em: 11 ago. 2020.

SOUSA, D. N. O que se entende por inclusão produtiva dos agricultores familiares? Um estudo de revisão bibliométrica. Cadernos de Ciência \& Tecnologia, Brasília, v.36, p.1-13, 2019b. Disponível em: https://bit.ly/2RrgGTj. Acesso em: 15 ago. 2019.

SOUSA, D. N; KATO, H. C. A; NIEDERLE, P. A; FREITAS, A. A; MILAGRES, C. S. F. Estratégias de comercialização do pescado da agricultura familiar para a alimentação escolar: a experiência da Embrapa no Tocantins. Cadernos de Ciência \& Tecnologia, Brasília, v. 36, n. 2, p. 1-18, 2019. Disponível em: https://bit.ly/33XBhBi. Acesso em: 25 out. 2019.

SOUSA, D. N; NIEDERLE, P. A. A produção científica brasileira sobre o que se entende por inclusão produtiva: um recorte temporal entre 2005 a 2016. Revista Desenvolvimento Social, Montes Claros, v. 1, p. 15-32, 2018. Disponível em: https://bit.ly/38eNQvq. Acesso em: 25 jun. 2019. 
SOUSA, D. N; SILVA, D. W; GEHLEN, I; MILAGRES, C. S. F. Programas governamentais de aquisição de alimentos da agricultura familiar no estado do Tocantins. Revista Brasileira de Gestão e Desenvolvimento Regional, v. 14, p. 252-264, 2018. Disponível em: https://bit.ly/2z5wFQw. Acesso em: 25 out. 2019.

WILKINSON, J. Mercados, redes e valores: $O$ novo mundo da agricultura familiar. Porto Alegre: Editora UFRGS, 2008.

WU, H; DING, B; YE, J. Desenvolvimento rural e a construção de novos mercados aninhados na China. In: MARQUES, F. C; CONTERATO, M. A; SCHNEIDER, S. (org.). Construção de mercados e agricultura familiar: desafios para o desenvolvimento rural. Porto Alegre: Editora UFRGS, 2016. p. 361-380.

YE, J.Z; WANG, W. The rise of nested market: Resistance to infinitive market and modern agriculture. Guizhou Social Science, v. 32, p. 48-54, 2011. Disponível em: https://bit.ly/2Rsj3We. Acesso em: 20 ago. 2019.

Diego Neves de Sousa. Doutor em Desenvolvimento Rural (UFRGS). Analista da Embrapa Pesca e Aquicultura. E-mail diegocoop@hotmail.com

Como citar: SOUSA, Diego Neves de. Os "novos" mercados e sua contribuição para a inclusão produtiva dos agricultores familiares no Tocantins. Redes (St. Cruz Sul, Online), Santa Cruz do Sul, v. 25, p. 2171-2184, 2020. ISSN 1982-6745. doi:https://doi.org/10.17058/redes.v25i0.15165.

Fontes de financiamento: CNPq, Sescoop e Embrapa. 